HUMANASE SOCIAIS

v.8 • N.3 • 2020 • Fluxo Contínuo

ISSN Digital: 2316-3801

ISSN Impresso: 2316-3348

DOI: 10.17564/2316-3801.2020v8n3p51-65
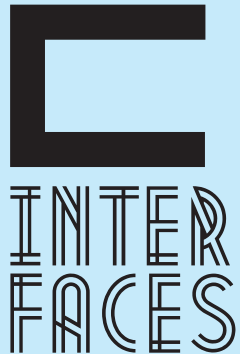

CIENTÍFICAS

\title{
UMA ABORDAGEM PRAXIOLÓGICA SOBRE A PRODUÇÃO E A REINVENÇ̃̃O DO SENTIDO
}

\section{UN ENFOQUE PRAXIOLÓGICO SOBRE LA PRODUCCIÓN Y LA REINVENCIÓN DEL SENTIDO}

\section{A PRAXIOLOGICAL APPROACH ON THE PRODUCTION AND REINVENTION OF MEANING}

\section{RESUMO}

Neste artigo insisto na possibilidade de interpretação do sentido por meio da investigação das práticas sociais. De início, explicito a produção do sentido por meio da síntese entre as ideias de Pierre Bourdieu acerca das práticas, destacando seu conceito de habitus e as análises de Peter Berger e Thomas Luckmann sobre a construção social da realidade. Na segunda parte, sob inspiração do psiquiatra Ronald Laing, uso casos hipotéticos, para mostrar como o sentido é descontruído pelas experiências de insegurança ontológica. Ao final, aciono o conceito de profanação, de Giorgio Agamben, para pensar a reinvenção do sentido e seus desdobramentos.

\section{PALAVRAS-CHAVE}

Sentido. Habitus. Insegurança Ontológica. Profanação. 


\section{RESUMEN}

En este artículo insisto en la posibilidad de interpretación del sentido por medio de la investigación de las prácticas sociales. En primer lugar, explicito la producción del sentido a través de la síntesis entre las ideas de Pierre Bourdieu acerca de las prácticas, destacando su concepto de habitus, y análisis de Peter Berger y Thomas Luckmann sobre la construcción social de la realidad. En la segunda parte, bajo la inspiración del psiquiatra Ronald Laing, uso casos hipotéticos, para mostrar cómo el sentido hegemónico es deshecho por las experiencias de inseguridad ontológica. Al final, acciono el concepto de profanación, de Giorgio Agamben, para pensar la reinvención del sentido y sus desdoblamientos.

\section{PALABRAS CLAVE}

Sentido. Habitus. Inseguridad ontológica. Profanación.

\section{ABSTRACT}

In this paper I insist on the possibility of interpreting meaning through the investigation of social practices. Inially, I explain the production of meaning through the synthesis of Pierre Bourdieu's ideas about social practices, highlighting his concept of habitus, and the analyzes of Peter Berger and Thomas Luckmann on the social construction of reality. In the second part, under the inspiration of psychiatrist Ronald Laing, I use hypothetical cases to show how meaning is deconstructed by experiences of ontological insecurity. In the end, I bring up the concept of profanation, by Giorgio Agamben, to think about the reinvention of meaning and its unfoldings.

\section{KEY-WORDS}

Meaning. Habitus. Ontological insecurity. Profanation. 


\section{INTRODUÇ̄̃̃O}

Em diversas correntes da teoria social, o sentido da existência e da ordem é compreendido como o resultado de operações mentais, discursos ou grandes estruturas transcendentais. Estas abordagens privilegiam ou uma subjetividade livre de condicionamentos exteriores e objetivos ou, ao contrário, grandes estruturas objetivas que ordenam a constituição social e subjetiva.

Numa tentativa de superar tais dicotomias, a teoria social contemporânea tem insistido em perspectivas que sintetizam abordagens objetivistas e subjetivistas (ALEXANDER, 1987). Fundindo e superando a dopagem cultural e a primazia subjetiva ou interacional, um conjunto variado de autores reafirma a importância de pensarmos as práticas como compostas por elementos, simultaneamente, estruturais e volitivos, constrangedores e capacitadores.

Andreas Reckwitz (2002) entende que as teorias contemporâneas focadas nas práticas complexificam e superam as abordagens mentalistas, textualistas e intersubjetivas de outrora. Embora possam ser entendidas como teorias culturais, estas teorias não dão conta das complexas relações entre prática e cultura. Para opor-se, acentua a existência de uma praxiologia culturalista na obra de diferentes autores contemporâneos ${ }^{3}$.

[...] the newness of the cultural theories consists in explaining and understanding actions by reconstructing the symbolic structures of knowledge which enable and constrain the agents to interpret the world according to certain forms, and to behave in corresponding ways. (RECKWITZ, 2002, p. 245-246).

Neste artigo insisto na possibilidade de interpretação do sentido por meio da investigação das práticas sociais. De início, explicito a produção do sentido por meio da síntese entre as ideias de Pierre Bourdieu acerca das práticas, destacando seu conceito de habitus e as análises de Peter Berger e Thomas Luckmann sobre a construção social da realidade. Na segunda parte, sob inspiração do psiquiatra Ronald Laing, uso casos hipotéticos, para mostrar como o sentido é descontruído pelas experiências de insegurança ontológica. Ao final, aciono o conceito de profanação, de Giorgio Agamben, para pensar a reinvenção do sentido e seus desdobramentos.

\section{A CONSTRUÇ̃̃̃O SOCIAL DO SENTIDO}

No pensamento de Pierre Bourdieu, o senso prático carrega duas concepções de sentido. Por um lado, estaria atrelado à possibilidade de criação de significado a partir dos instrumentos simbólicos disponíveis e, por outro, seria um conjunto de disposições que engajam corporalmente o sujeito no

3 São exemplos Pierre Bourdieu, Anthony Giddens, Harold Garfinkel, Bruno Latour, Charles Taylor, Theodore Schatzki, Judith Butler e o Foucault dos estudos sobre a ética antiga (CALHOUN apud PETERS, 2017, p. 243). Embora pertencentes a diferentes escolas de pensamento, o interesse pelo último Wittgenstein e/ou pelo primeiro Heidegger os une (CALHOUN apud PETERS, 2017, p. 244). 
mundo (CALHOUN apud PETERS, 2017, p. 177). Trata-se de uma junção entre sensação e significação ou, melhor dizendo, de uma relação dialética entre material e imaterial, interioridade e exterioridade. Disso resulta que o estudo da produção de sentido deve penetrar nos mecanismos de construção social da realidade nos múltiplos aspectos e dimensões em que estas esferas coagem e, ao mesmo tempo, servem como condições de possibilidade para a existência social.

Tal reflexão, seguindo os princípios metodológicos bourdiesianos, não deve partir das características individuais, mas da "intersubjetividade simbolicamente mediatizada" (CALHOUN apud PETERS, 2017, p.184). Para prosseguir neste caminho, buscarei entrelaçar as perspectivas deste autor com as de Peter Berger e Thomas Luckmann (1974). Se no primeiro reconhecemos o esforço de uma sociologia positivamente fundada pela síntese, por meio dos dois últimos compreendemos fenomenologicamente a construção subjetiva e intersubjetiva na vida cotidiana, numa teoria do conhecimento que emerge do olhar sobre os aspectos mais banais da vida rotineira. Traço em comum entre os três é a tentativa de reconstrução dos princípios intersubjetivos que guiam as relações sociais e, consequentemente, a construção do sentido ${ }^{4}$.

Evidente em Bourdieu - e também no pensamento de Giddens (1979) -, a dialética entre as estruturas sociais e as disposições individuais é o cerne da produção do sujeito e dos significados que este incorpora e atribui ao mundo. Tal como no postulado marxiano, segundo o qual "os homens fazem a sua própria história; contudo, não a fazem de livre e espontânea vontade, pois não são eles que escolhem as circunstâncias sob as quais ela é feita" (MARX, 2011, p. 25), os modos de agir, pensar e sentir sempre estão relacionados a uma estrutura que os cerca, tal como os marxistas e estruturalistas pensaram, mas é nesse contexto que a ação pode desenvolver-se criativamente, como pensaram os etnometodólogos, fenomenólogos, pragmatistas - ou mesmo certas vertentes do marxismo. Portanto, a sensação de estar no mundo é produto de uma dualidade ontológica.

Deve-se, então, atentar para o centro deste processo: as práticas sociais. É nelas que se expressa e se (con)forma o senso prático (BOURDIEU, 2011). Por meio deste conceito investigamos com mais profundidade a formação simbolicamente mediatizada da subjetividade. Subjetividade que não pode ser tomada por um a priori metafísico, mas pela prática dos indivíduos no mundo - com seus desdobramentos nos automatismos corporais, nos condicionamentos psicológicos e no engendramento de percepções.

É também para compreender as práticas sociais que Bourdieu desenvolve a ideia de habitus. Diferindo da concepção de hábito como repetição exaustiva, o habitus é resultado da dualidade da estrutura presente, como dissemos, tanto no pensamento do sociólogo francês quanto em Giddens (PETERS, 2011, p. 15). 0 conjunto de constrangimentos e capacitações estruturais produz disposições que são formadas e operam como "estruturas estruturadas predispostas a funcionar como estruturas estruturantes” (BOURDIEU, 2011, p. 87). Desse modo, o conhecimento objetivado serve como condição de possibilidade para a agência. Atrelando Bourdieu a Schütz (1979), pode-se dizer que o habitus também carrega consigo estoques de conhecimentos, subsídios para ação competente.

4 Embora Berger e Luckmann (1974) não abordem exatamente a questão discutida neste artigo, usarei suas concepções sobre a construção da vida social como ferramentas para tratar da produção do sentido por meio das práticas. 
Essa categoria não abarca somente as condições sociais do presente - como se as disposições hoje percebidas nos agentes fossem apenas produtos da nossa atual realidade social, política e cultural. Sua constituição deriva de processos históricos e contingentes que, como tais, fizeram-se por rupturas e continuidades. Tal historicidade também pode explicar o quão forte e cristalizado está na realidade, por vezes assemelhado a uma fantasmagórica estrutura que parece reavivar o passado.

Por se impor como uma "natureza", fugir do habitus que conforma "homens como homens" e "muIheres como mulheres", por exemplo, representa uma dura e exaustiva batalha contra algo que se manifesta como uma necessidade a-histórica e aliada ao "esquecimento". Ainda neste ponto, também podemos dizer que esta força resulta de sua manifestação opaca, do fato de não se apresentar como algo visível ou como uma racionalidade totalmente justificada, mas de ser uma estrutura pré-reflexiva pela qual o agente é envolvido.

A importância do habitus aqui decorre do fato de que ele não simplesmente estrutura as ações, mas que, pelo mesmo processo, se relaciona aos campos simbólicos dotados de um conjunto de sentidos. Funciona como condição de possibilidade para a dialética entre produção e incorporação de significados: ao internalizarmos as disposições historicamente objetivadas, encarnamos também os sentidos que subjazem ao mundo intersubjetivamente compartilhado, na medida em que os produzimos e reproduzimos nas nossas práticas. Dessa maneira, a praxiologia culturalista de Bourdieu entende a emergência do sentido por meio das práticas sociais, não como epifania de uma consciência fundadora.

Segue-se que a persistência e reprodução do habitus representa, também, a persistência do conjunto de sentidos hegemonicamente compartilhados. Estes, por sua vez, estruturam as práticas sociais, objetivando-se em instituições e constituindo o cotidiano comum. Na medida em que compartilha um mesmo habitus, um grupo ou classe social compartilha dos sentidos imbuídos nestas disposições, o que faz com que diferentes agentes vivam em um mundo comum. Essa correspondência entre o "meu mundo" e o dos outros nas relações sociais é uma parte do que chamamos de "segurança ontológica”, como veremos mais adiante.

Berger e Luckmann (1974, p.35), tratando fenomenologicamente destes temas, dizem que "a vida cotidiana se apresenta como uma realidade interpretada pelos homens e subjetivamente dotada de sentido para eles na medida em que forma um mundo coerente". Se, nesta passagem, os autores referem-se à "interpretação" da realidade por indivíduos imbuídos de fins pragmáticos, diremos, unindo a ideia ao pensamento de Bourdieu, que tal interpretação discursivamente articulada não é uma expressão fiel do habitus e do sentido materializado no senso prático, mas apenas a aparência destes. Isto porque, como dito anteriormente, o senso prático funciona por meio de um conjunto de regras tácitas, inconscientemente incorporadas, não pela forma de pressupostos discursivos para a ação. 0 que importa aqui é como a "sensação", aliada à "interpretação", de coerência do mundo está atrelada aos sentidos hegemonicamente compartilhados transmitidos pelo habitus.

A sensação é resultado do encontro entre o agente comum e um campo social. Os espaços sociais formados por agentes e instituições, funcionando como microcosmos de autonomia relativa, devem sua forma de estruturação às injunções intersubjetivas que conformam o habitus. 0 campo acadêmi- 
co, por exemplo, estrutura-se de um modo que, por ser naturalizado nas disposições adquiridas pelos que dele fazem parte, aparece aos agentes como dotado de coerência, se impondo como "normal". No entanto, para os trobiandeses estudados por Malinowski, escrever artigos para revistas acadêmicas, argumentar de modo tão polido e sistemático nas aulas e discussões ou mesmo frequentar aulas pode parecer algo justificação.

A (quase) perfeita coincidência entre a interioridade conformada pelo habitus e a exterioridade objetiva(da) joga o indivíduo numa illusio. Investido por ela, encara com seriedade todas as regras do seu microcosmo, independentemente de seu caráter arbitrário. A melhor metáfora para a illusio se encontra nos jogos. Segundo Bourdieu, "os jogos sociais são jogos que se fazem esquecer como jogos e a illusio é essa relação encantada com um jogo que é o produto de uma relação de cumplicidade ontológica entre as estruturas mentais e as estruturas objetivas do espaço social» (1996, p.139-140). Assim, os indivíduos agem como se suas regras tivessem estatuto de verdade, duelando com seus adversários como se o jogo fosse mais que o jogo - como se fosse a "vida”. Quando adaptados, seus movimentos são expressões de automatismos corporais, permitindo antecipações e criatividades limitadas pelas regras.

O encontro entre habitus e campo é o encontro entre história incorporada e história objetivada, daí porque esses microcosmos sociais são minimamente previsíveis para os que dele fazem parte: sua organização está em completa simetria com a organização das disposições individuais. Exterioridade e interioridade se confundem, dando ao agente a sensação de completa segurança ontológica. Desse modo há total consagração do mundo de sentidos intersubjetivos, o que gera segurança para que os agentes estruturem seus pensamentos e ações a partir das estruturas estruturadas.

Tida como normal e evidente, a realidade que consagra o sentido incorporado "impõe-se à consciência como maciça, urgente e intensa"; segundo os epígonos de Alfred Schütz, "é impossível ignorar e mesmo é difícil diminuir sua presença imperiosa" - "preciso falar com os familiares ou amigos ao redor", "preciso acreditar na existência dos instrumentos que uso no meu cotidiano", "preciso agir para conservar minha existência física": mais do que produtos da volição, essas "necessidades" são condições para estar no mundo (BERGER; LUCKMANN, 1974, p. 38). É neste momento que as estruturas condicionam nossa ação, dando sentido à vida, mas que, ao mesmo tempo, a agência converte positivamente os conteúdos objetivados que nos cercam. Se o sentido é construído nas atividades mundanas, não pode estar desvencilhado das práticas, mesmo as mais triviais.

A presença "maciça, urgente e intensa" da realidade da vida cotidiana, unindo mais uma vez Berger e Luckmann à Bourdieu, não se impõe a uma consciência desvencilhada das atitudes corporais. Ela atravessa os gestos, o modo de andar, os afetos e a sensibilidade. Sabendo de um atraso para um compromisso importante, posso ser tomado pela ansiedade e atuar de modo embaraçado. Nesta situação, meu corpo age automaticamente, como se a urgência da necessidade social fosse uma necessidade do seu ser. 0 que é produto do arbitrário social, aparenta-se a uma força da natureza, um instinto fictício que corrobora para a reprodução das estruturas sociais.

Como disse, o "sentido" possui uma dualidade essencial, pois é tanto significação do mundo quanto incorporação. Ele está imbuído no senso prático que, por sua vez, é resultado da relação entre 
habitus e campo, incorporação e objetivação. Em sua dualidade "prática”, não pode ser encontrado somente nas consciências (tomadas separadamente da corporeidade) ou nos discursos de uma época, mas na intersubjetividade simbolicamente mediatizada. É por meio dela que os indivíduos se envolvem numa illusio, na normalidade da vida cotidiana. Em contrapartida, seu contrário terá a aparência de absurdo.

\section{A RUPTURA COM O SENSO PRÁTICO COU A CONSTRUÇ̃̃O SOCIAL DO ABSURDO]}

A construção social do sentido está diretamente relacionada à nossa experiência nos contextos sociais que compomos como agentes que absorvemos e produzimos o mundo. Produto da dualidade da estrutura (PETERS, 2011, p. 15), o senso prático implica, como dissemos, uma quase total correspondência entre a estrutura social (simbólica e material) e a nossa subjetividade. A essa cumplicidade damos o nome de segurança ontológica.

Segurança porque, tomando o mundo como óbvio, nos sentimos confortavelmente dispostos para agir segundo uma realidade que acreditamos se apresentar sem riscos para nossas existências. Além de pensarmos a conhecer, seus constrangimentos e capacitações fazem com que a interpretemos como ordenada e coerente. Desse modo, sentido, senso prático e segurança ontológica são elementos que devem estar combinados para uma existência normal e dentro dos padrões de ação que a ordem social nos impõe.

Se o que disse anteriormente gozar de consistência lógica, pode-se afirmar que a experiência da ausência de sentido implica uma mirada oposta: em direção aos casos em que não há uma cumplicidade entre subjetividade e objetividade, mas uma diferença entre os modos de agir, pensar e sentir dos sujeitos e as estruturas sociais que os cercam.

Embora tenha pontilhado os processos em que as estruturas sociais investem radicalmente os indivíduos, a incorporação do habitus nunca é perfeita, sem falhas ou resistências. Ele não afeta sujeitos totalmente passivos, fielmente dóceis aos comandos de uma estrutura (PETERS, 2017, p. 105). Ao contrário, estamos sempre transformando os conteúdos que nos são impostos. Essa característica remete à interpretação praxiológica da distinção saussuriana entre língua e fala: a língua (estrutura) não é simplesmente reproduzida nas falas (agência), mas transformada continuamente. Nunca haverá total cumplicidade entre subjetividade e objetividade, entre agência individual e estrutura. Em termos psicológicos: nunca haverá total segurança ontológica. Por isso que a experiência no mundo sempre representará algum grau de risco para o status quo.

Cunhada pelo psiquiatra Ronald Laing, a noção de insegurança ontológica remete a esta crise da experiência de obviedade do mundo. Ela é o oposto da sensação de conforto e amparo. No livro The Divided Self, ele a descreve em seus detalhes, mostrando que se trata do sentimento de quebra da segurança com os outros, com o mundo material e consigo, o que faz com que o indivíduo se sinta mais irreal que real, mais morto que vivo (LAING, 1974, p. 42).

The whole 'physiognomy' of his world will be correspondingly different from that of the individual whose sense of self is securely established in its health and validity. Related- 
ness to other persons will be seen to have a radically different significance and function. To anticipate, we can say that in the individual whose own being is secure in this primary experiential sense, relatedness with others is potentially gratifying; whereas the ontologically insecure person is preoccupied with preserving rather than gratifying himself: the ordinary circum stances of living threaten his low threshold of security.

A partir das experiências clínicas, Laing mostrou que a desconfiança no mundo "real” pode se desdobrar em três tipos de experiências, nomeadas engulfment, implosion, petrification e depersonalization ${ }^{5}$ pelo autor.

Essa ruptura com o vínculo entre senso prático e segurança ontológica produz uma quebra do sentido da existência imbuído nos nossos corpos e ações. A certeza de vivermos em um mundo coerente e justificado é substituída por um sem-número de indagações acerca da natureza das coisas e dos conteúdos que subjazem aos véus ideológicos da realidade da vida cotidiana. Mas se, no extremo, tal experiência se converte em um ceticismo radical sobre a vida, em grande parte dos casos ela se apresenta em graus variados, como resultado de pequenas rupturas com os vínculos que constituem a illusio.

Nos contextos de descontinuidade entre subjetividade e mundo, o sentido - implícito no mundo que vejo e toco - é atingido pela mesma multiplicidade de indagações que falamos anteriormente. Nas vivências esquizo, ele pode se perder totalmente, sendo substituído por justificativas que gerem algum tipo de conforto existencial, mesmo que precário. Nos casos não patologizados, pode ser atravessado por um questionamento filosófico, inclinado para a sua crítica integral (algo assemelhado à náusea sartreana), ou se expressar por um distanciamento das condições cognitivas do agente - isto é: casos em que podemos interpretar o mundo como arbitrário sem que nosso corpo seja refém da náusea. Aqui importam as situações nas quais há uma descrença acerca do sentido, mas em que esse mesmo estranhamento do mundo possa conduzir a uma ressignificação da vida e, em consequência, a uma transformação da cognição e da ação individuais.

Antes disso, gostaria de analisar as experiências geradoras da construção social da ausência de sentido. Tentarei traçar os modos pelos quais se engendram, a partir das práticas sociais, as experiências de questionamento do mundo objetivado. Usaremos a ideia, citada acima, de que a insegurança ontológica se expressa como suspeita dos outros, da realidade material e de nós mesmos. Todavia, fugiremos dos exemplos de Laing, para esboçar, arriscadamente, casos hipotéticos, embora comuns nas vivências de quaisquer indivíduos, em que a segurança ontológica é rachada em parte ou totalmente.

Sabemos que o processo de socialização, tal como estudado pela sociologia, ocupa fundamental papel na constituição cognitiva e moral individual. A socialização primária, aquela que se inicia na mais tenra infância, interioriza nos indivíduos os conteúdos que servirão como condições de possibilidade para o pensar, o sentir e o agir, inclusive nas fases mais adiantadas da vida. Sendo assim, as violências sofridas durante a primeira socialização podem marcar sobremaneira os corpos, tornando-se gatilhos sempre dispostos ao acionamento, principalmente durante algum tipo de crise psicológica.

5 Para preservar as definições originais, optei por citar os conceitos na língua inglesa. 
A desconfiança em relação aos outros, causa e/ou resultado da insegurança ontológica, pode estar, portanto, fundamentalmente relacionada às experiências das primeiras socializações.

Violências sofridas por crianças pertencentes às minorias étnicas ou que têm pais que professam religiões estigmatizadas podem ser bons exemplos da construção social desse tipo de insegurança em relação aos outros. A interpretação dos episódios de agressão é construída por essas pessoas como uma expressão da ausência de estima no seio social. 0 efeito revelar-se-á na percepção de que a sua vida vale menos que a dos demais, o que pode se materializar na resignação com o trágico destino ou em lutas pelo reconhecimento de sua dignidade humana. Em ambos os casos, a força da experiência de violência marcará os indivíduos como uma ferida moral e cognitiva, que será possivelmente maculada em fases mais adiantadas da existência.

Podemos mostrar, prosseguindo pelas experiências primeiras, como as problemáticas familiares também afetam as relações e percepções sobre os outros indivíduos. A importância das relações com os pais constitui um exemplo interessante. Uma vez que estes são, ao menos durante os primeiros anos da infância, os principais referenciais para a vida, a ausência do seu reconhecimento pode exercer um forte dano à segurança que o indivíduo tem com o mundo. Ora, se as pessoas incumbidas socialmente de garantirem o conforto existencial do sujeito tornam-se os algozes de sua autoconfiança, quem mais poderia ser confiável? Esta pode ser a indagação atormentadora com a qual vivem aqueles que sofreram violências no âmbito familiar.

Se estamos insistindo na produção da insegurança ontológica durante a infância é mais para sublinhar a importância das primeiras socializações nos estados psicológicos posteriores do que para demarcar cirurgicamente o modo pelo qual os indivíduos se tornam constantemente inseguros quanto aos outros. Este fenômeno pode nascer de diversas maneiras, durante os fluxos socializadores que o indivíduo experimenta durante toda a sua vida.

A insegurança em relação aos outros resulta numa acentuada dificuldade de se adaptar às vivências coletivas. A intensificação das desconfianças também pode se expressar em constantes paranoias, como se todos estivessem contra o sujeito - que, em alguns casos, pode sentir-se numa espécie de big brotherorwelliano.

Conquanto, representam situações de intenso sofrimento psíquico, tais experiências também servem de cenário para a criação de narrativas alternativas. Um paranoico pode produzir um sentido para a sua vida a partir da percepção de que os outros o vigiam. Disto podemos pensar que o indivíduo sempre está à procura do sentido, mesmo quando tomado pelas patologias de nossa época - "se me chamam de louco, é preferível acreditar na minha própria justificativa para isso, não na dos que me estigmatizam". Esta procura não é algo simplesmente mentalizado, fruto de uma consciência inquieta e filosoficamente sofisticada, mas uma necessidade corporal de conforto. Por isso, as justificativas alternativas carregam teorias precárias sobre a vida - embora tão arbitrárias quanto as socialmente partilhadas. Tudo se passa como se minha experiência fosse dotada de sentido próprio.

Além da insegurança em relação aos outros, experiências de ruptura resultam em um desconforto motivado por uma percepção distorcida da realidade material. A causa dessa insegurança pode ser a vivência de situações nas quais ficamos em face de rupturas inesperadas com a materialidade do mundo em que vivemos. É possível que alguém que presencie um desabamento de um prédio em que 
morava, por exemplo, viva traumatizado a partir deste episódio. De maneira que, quando em contato com qualquer estrutura sólida, questione sua segurança.

A possibilidade do desabamento de uma estrutura física onde o indivíduo está pode ser a metáfora para um desmoronamento psicológico, pois, como dissemos anteriormente, o sentimento de obviedade do mundo está diretamente ligado a uma relação de quase completa cumplicidade entre a imaterialidade do mundo simbólico e a materialidade do espaço onde o agente está. Qualquer ruptura entre esses polos resulta numa sensação de desconforto com a realidade imediata, uma vez que ela não é mais previsível. Nestes casos, o senso prático sofre um questionamento interno, seu veículo, o corpo, já não é mais reflexo de um mundo coerente e justificado, mas de uma realidade perigosa, na qual não se pode jogar simplesmente por meio de automatismos e antecipações condicionadas.

As diversas experiências de produção da insegurança em relação ao ambiente físico geram múltiplas reações psicológicas. O sujeito pode não só evitar lugares que causam insegurança, como usar de estratégias para se salvar dela. Nestes casos, tanto as atitudes de evitamento quanto as de resolução fugirão das performances tomadas como normais, pois os modos de agir não estarão em cumplicidade com o senso prático difundido pelo habitus compartilhado.

Finalmente, podem existir casos de suspeição a respeito de si mesmo. Algumas das possíveis causas estão relacionadas a experiências em que o corpo do indivíduo foi violado. Vítimas de estupro podem achar que não têm mais controle sobre si e questionarem sua autonomia, por pensarem que a qualquer momento sua possibilidade de ação será negada pela ação negativa de outrem. Nestes casos, evitamentos, percepções distorcidas sobre seus próprios corpos, desconfiança em relação aos outros, em suma, todos os efeitos já descritos nos outros exemplos podem se expressar no sujeito.

Os casos discutidos envolvem situações em que a sensação de obviedade do mundo é destruída. Em seu lugar, inseguranças e riscos atacam as subjetividades dos indivíduos. O senso prático, como mundanidade incorporada e engenho de significação, é questionado na relação do indivíduo com a realidade material e simbólica que o envolve. 0 sentido tácito apre(e)ndido durante a socialização, nos diversos mundos que os agentes compõem, é também questionado. A exacerbação destas experiências pode levar a sua perda, pois todas as disposições transmitidas, com todos os seus significados implícitos, são destituídas de realidade. Tomado até então como coerente e ordenado, o mundo prático é substituído por um mundo absurdo e assistemático, onde tudo pode representar perigo.

\section{DESDOBRAMENTOS DA REINVENÇ̃̃O DO SENTIDO}

Das inúmeras vantagens que a lida com o tema da ausência de sentido a partir da praxiologia culturalista tem, duas devem ser destacadas. A primeira é a possibilidade de vermos o ceticismo resultante da insegurança ontológica como uma produção social. Como mostramos, o questionamento da realidade não surge por uma pura epifania, desligada do contexto de inserção do agente. É no confronto entre subjetividade e experiência social que há a ruptura da illusio.

A segunda vantagem, decorrente da primeira, está na possibilidade de entendermos a estrutura social como alicerce sobre o qual é construído um sentido alternativo para a vida. Diferentemente 
das justificativas alternativas das vivências esquizo, estamos nos referindo à produção do sentido em negociação com o mundo intersubjetivo hegemônico, não pela fuga completa dele. Isto se desdobra numa série de problemáticas que não podem ser desvencilhadas da necessidade do bem viver. Seríamos sadistas se não pensássemos os efeitos da profanação da linguagem e das práticas como obstáculo para uma vida minimamente confortável.

Propomos pensar o tema, tendo estas questões em mente, a partir de uma poesia de Manoel de Barros. Ela sintetiza as possibilidades e problemáticas envolvidas numa postura profanadora.

As coisas tinham para nós uma desutilidade poética. Nos fundos do quintal era muito riquíssimo o nosso dessaber. A gente inventou um truque pra fabricar brinquedos com palavras. O truque era só virar bocó.

(BARROS, 1996, p. 11).

A poesia, publicada no Livro sobre nada (BARROS, 1996), compõe uma série de outros escritos do autor, cuja relação com o tradicionalismo do campo convive com o questionamento do mundo objetivado. Ele indaga as ontologizações do senso comum, provocando docemente o leitor a respeito dos nomes, das coisas, das práticas. A poesia de Manoel de Barros questiona a illusio de que fala Bourdieu, colocando em seu lugar a radical subversão da linguagem. Não pensa ele numa reconstrução racional de si e do mundo, mas na desconstrução quase absoluta, almejando retornar ao "criançamento das palavras” (1996, p. 47). Não seria exagero dizer que sua poesia se move por meio de uma hiperreflexão pueril.

Ao trazer o tema da profanação para sua poesia, estamos nos referindo ao processo que, como disse Giorgio Agamben, restitui aos indivíduos aquilo que foi dado aos deuses (2015, p. 65). Nesse sentido, questiona toda a sacralização da realidade da vida cotidiana, por isso devolve a si e a todos nós a possibilidade de renomear, reclassificar, repensar, refuncionalizar as palavras e as coisas. 0 mundo de sua poesia não é ordenado e coerente, mas docemente perturbado por indagações que parecem produzidas por uma criança.

Disto resulta, como no trecho citado, a possibilidade de pensarmos que as coisas têm uma "desutilidade poética" e, do mesmo modo, fazer do "dessaber" algo "riquíssimo". Usando seus versos como metáforas sociológicas, podemos pensar que o poeta sugere que brinquemos com as disposições impostas durante a socialização. Acontece que sua ingenuidade poética não possibilita questionarmos, como faria a praxiologia culturalista, as possibilidades de tal desconstrução. Fazer das palavras brinquedos, como diz, não pode ser um simples ato de quem decide abandonar o mundo e, sim, uma prática inserida numa estrutura.

No entanto, sem negar uma profusão de temas sociológicos e filosóficos presentes em sua obra, tomarei a possibilidade desconstrucionista, resultante do desejo de fabricar brinquedos com palavras, como um meio de questionar as funcionalidades que têm as palavras e as coisas no cotidiano. Tratar-se-á de um questionamento a respeito da cumplicidade entre subjetividade e objetividade, uma vez que aqueles conteúdos internalizados não contemplam o ser, mas são apenas objetivações arbitrárias da linguagem e das práticas. 
Mesmo o seu delicado subjetivismo poético reconhece a dificuldade do radical e incessante questionamento - ou, para nós, da desconstrução da realidade da vida cotidiana. Como diz o poeta, tal posição nos impele a virarmos bocó. Esta alusão de Barros coloca o seguinte dilema a respeito da reconstrução de sentido para a vida a partir do questionamento da realidade: se pensamos e agimos em conformidade com os conteúdos simbólicos e materiais dos nossos campos, somos considerados atores competentes, caso contrário: somos infantilizados ou, nas suas palavras, tomados como bocós. Este problema nunca se apresenta de forma tão dicotômica na empiria - o indivíduo pode ser, ao mesmo tempo, normalizado e marginalizado, a depender do campo em que está inserido -, mas, sem dúvidas, nos mostra dificuldade de um bem viver dissidente.

Como, então, dar um sentido crítico para a vida sem viver atormentado pelas coerções e vexações sociais? Motivado por esta indagação lançarei alguns comentários sobre a possibilidade da produção criativa de si. Produção negociada, uma vez que, como diria Bourdieu, o sujeito não pode ser desligado das raízes estruturais, como uma subjetividade totalmente nômade.

Para tanto, pensarei a criatividade como um elemento essencial de toda atividade humana. Sintetizando Joas e Bourdieu, Benjamin Dalton (2004, p. 6) mostrou como a inventividade prática não está restrita aos momentos em que as disposições incorporadas falham, ela funciona mesmo onde os bourdiesianos veriam a primazia da reprodução. Desta forma, pensarmos o hábito, ou o habitus, implica manejarmos a noção de criatividade, assim como o contrário também é verdadeiro.

Refletir acerca da criatividade, seguindo-se ao tensionamento entre agência e estrutura, nos conduz à problemática da invenção e da reprodução social. A respeito do nosso tema, podemos pensar algumas coisas. A primeira é que a produção de um novo sentido a partir das experiências de insegurança ontológica não significa que ele está totalmente à margem das produções sociais reificadas. A invenção, apesar de se diferenciar criticamente daquilo a que se opõe, necessita da diferença para se afirmar. Só podemos criticar uma verdade social se, a partir dela, pudermos expor nossas divergências. A ilusão de uma atividade crítica livre cai, inevitavelmente, em um subjetivismo desligado dos constrangimentos simbólicos e materiais aos quais estamos submetidos.

Por outro lado, a construção de um novo sentido tenderá à reificação social. Uma vez que estamos tratando das práticas sociais, sabemos que, por mais dissidentes que sejam, se inclinam à reificação, na medida em que passam a ser rotinizadas por indivíduos e grupos. Daí porque movimentos que surgiram como uma crítica aos dispositivos de poder acabaram se tornando politicamente estéreis e reféns da impossibilidade de autocrítica. Atualmente, o incessante desenvolvimento da indústria cultural também tem forte poder de banalização das aspirações à crítica, por fazer das dissidências conteúdos culturais desejáveis ao mundo de consumidores.

A partir desses dois comentários, chegamos a uma concepção pessimista sobre a possibilidade de uma vida radicalmente dissidente, que, de algum modo, se assemelha às posições de Georg Simmel e sua crítica à modernidade. Posto que sempre precisamos das formas ${ }^{6}$ para vivermos, sua autonomia e reificação é o “destino universal de nossos conteúdos culturais” (VANDENBERGHE, 2005, p. 180).

6 Utilizo a noção de "forma" sem me prender à influência neokantiana na teoria simmeliana das formas de associação, com ela me refiro a todos os conteúdos culturais objetivados. 
O pessimismo sociológico, no entanto, não retira a potência política de nossa ação sobre nós mesmos e sobre o mundo. Apesar de todo o sentido produzido e incorporado tender à reificação através de nossas próprias práticas, constituindo um novo senso prático, as criatividades cotidianas nos livram de uma infinidade de violências e limitações socialmente impostas. Se a ideia de uma crítica incessante é contrariada por tudo que dissemos até aqui, a ação criativa e negociada nos diversos campos que compomos ainda é a melhor forma de reconstruirmos a nós mesmos.

\section{REFERÊNCIAS}

ALEXANDER, J. O novo movimento teórico. Revista Brasileira de Ciências Sociais, n. 2, 1987.

AGAMBEN, Giorgio. Profanações. São Paulo: Boitempo, 2007.

BARROS, Manoel de. Livro sobre nada. 3. ed. Rio de Janeiro/São Paulo: Record, 1996.

BERGER, Peter; LUCKMANN, Thomas. A construção social da realidade: tratado de sociologia do conhecimento. 2. ed. Petrópolis: Vozes, 1974.

BOURDIEU, Pierre. 0 senso prático. Petrópolis: Vozes, 2011.

BOURDIEU, Pierre. Razões práticas: sobre a teoria da ação. Campinas: Papirus, 1996.

DALTON, Benjamin. Habitus, creativity, and the social products of creative action: revising Joas, incorporating Bourdieu. Sociological theory, v. 22, n. 4, p. 602-622, 2004.

GIDDENS, A. Central problems in social theory: action, structure and contradiction in social analysis. London: Macmillan, 1979.

LAING, Ronald. The divided self: an existential study in sanity and madness. Harmondsworth: Penguin, 1974.

MARX, Karl. 018 brumário de Luís Bonaparte. São Paulo: Boitempo, 2011.

PETERS, Gabriel. Agência, estrutura e práxis: uma leitura dialógica da teoria da estruturação de Anthony Giddens. Teoria \& Sociedade, Belo Horizonte, v. 2, n. 19, p.8-39, 2011. Semestral.

PETERS, Gabriel. A ordem social como problema psíquico: do existencialismo sociológico à epistemologia insana. São Paulo: Annablume, 2017. 
RECKWITZ, Andreas. Toward a theory of social practices: a development in culturalist theorizing. European Journal of Social Theory, v. 5, n. 2, p. 243-263, 2002.

SCHÜTZ, Alfred. Bases da fenomenologia. In: WAGNER, Helmut R. (Org.). Fenomenologia e relações sociais. Rio de Janeiro: Zahar, 1979.

VANDENBERGHE, Frédéric. As sociologias de Georg Simmel. Bauru \& Belém: Edusc: 2005. 


\section{(2) (1) (-)}

Este artigo é licenciado na modalidade acesso abertosob a Atribuição-Compartilhalgual CC BY-SA

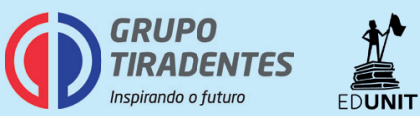

